\title{
Notalgia Paresthetica: A Rare Cause of Neuropathic Pain
}

\author{
Emrah Kovalak' (iD, Çiğdem Aydoğan²
}

Notalgia paresthetica is a clinical condition characterized by burning and stinging pain accompanied by an itchy hyperpigmented skin lesion in the distribution area of spinal nerves T2-T6. Its etiology is not completely understood. It is a relatively common pathology that is often overlooked. Patients usually refer to dermatology clinics with complaints of pruritus, and the diagnosis is usually delayed, or some symptoms can go unnoticed. Early diagnosis and treatment are important because notalgia paresthetica reduces the quality of life. In this case study, we present a 65-year-old male patient who referred to our clinic and discussed this case for research.

Keywords: Neuropathic pain, notalgia paresthetica, hyperpigmentation

ORCID IDs of all authors: E.K. 0000-0003-01219082; C.A. 0000-0001-5476-9454.

'Department of Orthopedics and Traumatology, Süleyman Demirel University School of Medicine, Isparta, Turkey

${ }^{2}$ Clinic of Physical Medicine and Rehabilitation, Artvin State Hospital, Artvin, Turkey

Address for Correspondence:

Çiğdem Aydoğan

E-mail: cigdemaydogan@me.com

Received: 19.10 .2017

Accepted: 02.01.2018

C Copyright 2018 by Available online at istanbulmedicaljournal.org

\section{Introduction}

The etiology of notalgia paresthetica has not yet been fully elucidated. However, notalgia paresthetica is defined as a disease characterized by neuropathic pain accompanied by dysesthetic symptoms, such as burning, stinging, tingling, pruritus, and numbness (1). Hyperpigmentation of the skin localized to the painful region, which is not accompanied by primary dermatologic pathology, is the most striking clinical finding $(1,2)$.

Notalgia paresthetica was first described in 1934 by the Russian neurologist Michail Astwazaturow as a clinical picture presenting with a painful, itchy hyperpigmented skin lesion usually localized to the dermatome distribution of the spinal nerves T2-T6. Notalgia paresthetica is considered to be a frequently encountered but easily overlooked condition, although its actual incidence remains unknown $(2,3)$.

Notalgia paresthetica mostly has a benign nature; however, because it reduces the quality of life, has a hereditary form, albeit rare, and is accompanied by multiple endocrine neoplasia, early diagnosis and screening for accompanying conditions is important (3). Diagnosis and treatment of a rare clinical presentation are noted in this case report.

\section{Case Report}

A 65-year-old man was admitted to the physical medicine and rehabilitation polyclinics with complaints of pain, burning, stinging, and pruritus on his back for the past 6 months.

Background and family history of the patient did not exhibit any specific conditions. Physical examination revealed a hyperpigmented macular skin lesion $10 \times 7 \mathrm{~cm}$ in size located under the left scapula in the dorsal region (Figure 1. a, b).

Complaints of burning and stinging by the patient were evaluated with pre-diagnosis of neuropathic pain, and diagnosis was made based on the Leeds Assessment of Neuropathic Symptoms and Signs (LANSS) scale. The LANSS scale included seven domains that assessed pain characteristics and sensation. This combines five simple questions and two examination findings to give a score for pain out of 24 , with a score $\geq 12$ suggesting a neuropathic component (4). The Turkish version of the LANSS scale has been validated (5). The symptom score was recorded as 19. The patient had increased thoracic kyphosis, and paravertebral muscle spasm was present on the side of the skin lesion. Laboratory findings for hemogram, sedimentation, C-reactive protein, and routine biochemical tests were normal. Only degenerative changes were observed in thoracic magnetic resonance imaging (MRI) (Figure 1c). 

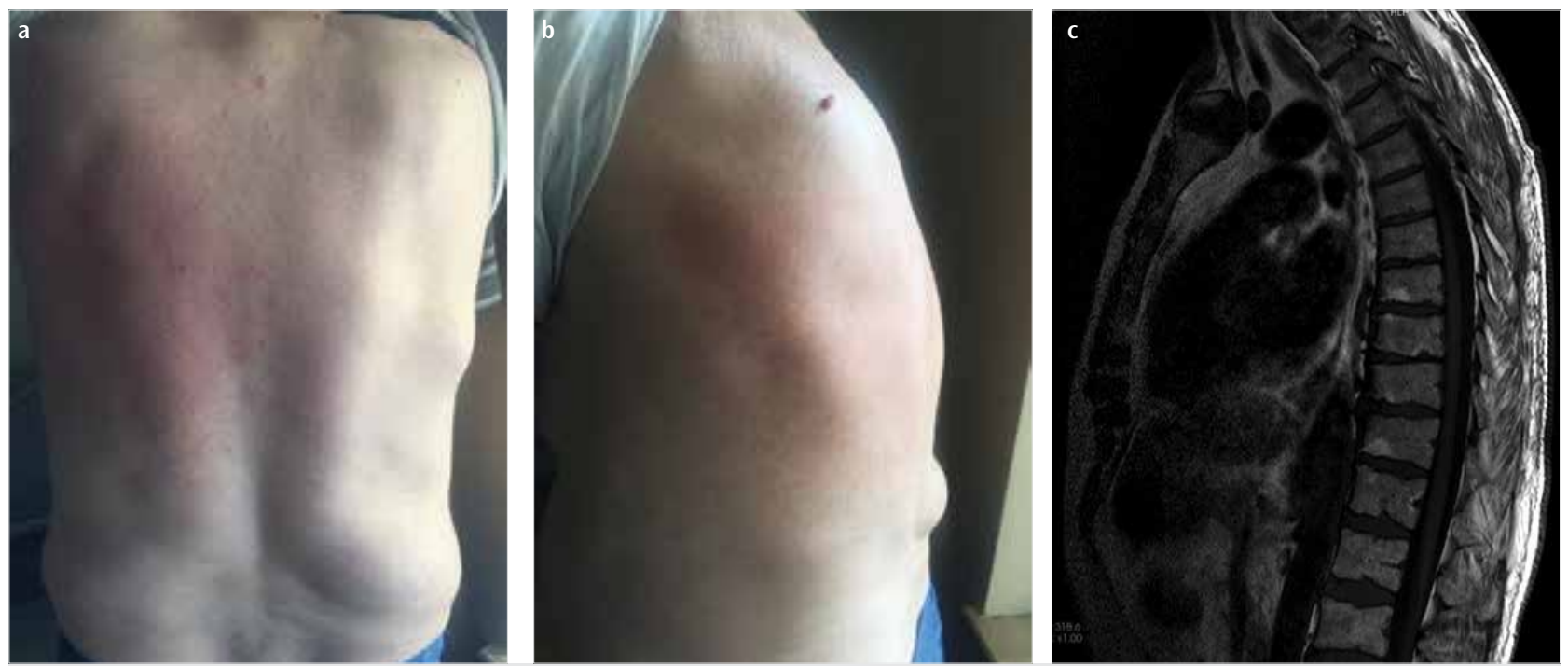

Figure 1. a-c. Hyperpigmented lesion in the left scapular region from the back of the patient (a); Hyper-pigmented lesion in the left scapular region from the left side of the patient (b); T1 weighted sagittal dorsal spine MRI image demonstrated spondylosis (c)

The patient was referred to a dermatology clinic for a differential diagnosis. Notalgia paresthetica was considered in the preliminary diagnosis, and gabapentin (Neurontin; Pfizer, Freiburg, Germany) was initiated at $600 \mathrm{mg} /$ day and gradually increased to $1800 \mathrm{mg}$ /day over 12 days. In addition, 10 sessions of $20 \mathrm{~min} /$ day high-frequency transcutaneous electrical nerve stimulation (TENS) and exercises were performed to increase and strengthen joint range of motion. A dual-channel high-frequency $(80 \mathrm{~Hz})$ asymmetric, biphasic TENS was applied at $30 \mu$ s pulses for 20 min with $4 \times 5 \mathrm{~cm}$ surface electrodes. The intensity of TENS was set to feel a slight tingling sensation.

At the first month of follow-up, complaints of pain, stinging, and numbness by the patient were seen to clinically improve. Medical treatment was continued for 6 months. The skin lesion did not regress at the end of treatment. The patient was given detailed information about the disease, and approval for using the disease in scientific research was granted. Approval from the local ethics committee was not obtained to protect the patient's identity.

\section{Discussion}

Notalgia paresthetica is a relatively common but often overlooked pathology. It is 2-3 times more frequently observed in men than that in women. It mostly develops during the fifth and sixth decades of life $(2,3)$.

The clinical findings of notalgia paresthetica include pruritus, burning, stinging, and dysesthesia in a localized region, occurring most often in the lower third of the scapulae that correspond to the dermatome distribution of the T2-T6 spinal nerves and the paravertebral area, as well as in the cervical region, hairy skin, and shoulders $(2,3)$.

Pagliarello et al. (6) conducted a study with 65 patients and detected lesions in the thoracic (41.5\%), scapular (26.2\%), cervical rate of these lesions was found to be 1.6 times higher in women than that in men. The authors also noted that the skin lesions are more diffuse among women, and worse prognosis was observed in patients with a high body mass index (6).

Diagnosis of notalgia paresthetica is usually delayed or even overlooked because patients refer to dermatology clinics primarily due to complaints of pruritus. The most common symptom is itching, and the most common neurological finding is hypoesthesia in the center of the lesion, as well as hyperesthesia that is occasionally seen. Skin lesions usually do not cross the midline. Intermittently, atrophic and keratotic macular lesions and signs of itching on the skin around the painful area are observed $(7,8)$.

Although the pathogenesis of the disease is not completely known, genetic susceptibility, increased dermal innervation, visceral reflex mechanisms, sensory neuropathy, and dorsal spinal nerve compression have been implicated (9). It is also considered that histamine released by the irritation of sensitive skin may cause itchiness (1).

Entrapment of the spinal nerves between T2 and T6 due to degenerative changes in the vertebrae, herniated nucleus pulposus, compression fractures, and other pathologies appear to be major causes in the etiology of notalgia paresthetica $(7,10)$. Genetic transitional forms of the disease and other forms associated with multiple endocrine neoplasia have also been reported (10).

There is no single clinical finding or laboratory test that allows a definitive diagnosis of notalgia paresthetica to be made. Itchy pigmented macular skin lesions that do not cross the midline but accompany pain and paresthetic complaints in the T2-T6 spinal nerves are pathognomonic (10).

Radiological examinations mostly reveal cervical and thoracic degenerative changes. In a study evaluating spinal pathologies in 43 patients using MRI, Savk et al. (11) reported degenerative disc 
hernias in $24.6 \%$ of the cases, degenerative changes in the thoracic vertebrae in $32.8 \%$, and degenerative changes together with thoracic disc hernias in $3.3 \%$.

In their study with 10 patients, Savk et al. (12) reported that electrophysiological examinations have normal findings in all patients. Since the diagnosis of the disease is mostly clinical, an electromyographic examination was not performed in our case. Electroneuromyographic studies performed in other studies also mostly provide normal findings. In the same study by Savk et al. (12), histopathological examination revealed a hyperkeratosis of the epidermis in a patient as well as extensive inflammation and melanophages in the papillary dermis in all patients. Histopathological examination was not performed in the present case. Skin disorders including atopic dermatitis, post-inflammatory hyperpigmentation, prurigo nodularis, and macular amyloidosis should be considered in the differential diagnosis (13).

Systemic and local agents have been used for the treatment of notalgia paresthetica. Topical capsaicin, corticosteroids, tacrolimus, and local anesthesia drugs can be used $(1,14)$. Antiepileptic drugs, such as gabapentin, pregabalin, oxcarbazepine, and tricyclic antidepressants, are preferred for the treatment of neuropathic pain. Antihistamines can be prescribed to relieve complaints of pruritus (14).

In another study conducted by Savk et al. (15), TENS therapy was shown to be effective in 15 patients. Maari et al. (16) administered botulinum toxin to 10 patients to prevent substance $P$ release to reduce the symptoms of pruritus and neuropathic pain and compared the results with a placebo group with an equal number of patients. The authors found no difference between the groups in terms of the symptoms of pruritus and the extent of hyperpigmentation (16). Tension and strengthening exercises on the lower back, rhomboid, pectoralis major, and latissimus dorsi muscles have been shown to be beneficial (17). In a single-case study, Subasi et al. (18) performed dry needling on the fibrous bands in the dorsal region combined with kinesio taping on macular skin lesions using the inhibition technique and found the treatment to be effective.

\section{Conclusion}

Owing to neuropathic pain complaints, rather than dermatology, patients with notalgia paresthetica may refer to other branches of medicine, such as physical medicine and rehabilitation, neurology, orthopedics and traumatology, brain and neurosurgery, and algology. A multidisciplinary approach is important in these patients. Positive outcomes can be achieved with early diagnosis and treatment.

Informed Consent: Informed concent was obtained from the patient who participated in this study.

Peer-review: Externally peer-reviewed.

Author Contributions: Concept - E.K., C..A.; Design - E.K., C..A.; Supervision E.K., C.A.; Resource - E.K., C.A.; Materials - E.K., Ç.A.; Data Collection and/or
Processing - E.K., C..A.; Analysis and/or Interpretation - E.K., C..A.; Literature Search - E.K., C..A.; Writing - E.K., C..A.; Critical Reviews - E.K., C..A.

Conflict of Interest: The authors have no conflict of interest to declare.

Financial Disclosure: The authors declared that this study has received no financial support.

\section{References}

1. Chiriac A, Podoleanu C, Moldovan C, Stolnicu S. Notalgia Paresthetica, A Clinical Series and Review. Pain Pract 2016; 16: 90-1. [CrossRef]

2. Pleet AB, Massey EW. Notalgia paresthetica. Neurology 1978; 28 : 1310-2. [CrossRef]

3. Karahan AY. Gabapentin and TENS in the Treatment of Notalgia Paresthetica: A Case Report. J PMR Sci. 2012; 15: 86-8.

4. Bennett M. The LANSS Pain Scale: the Leeds assessment of neuropathic symptoms and signs. Pain 2001; 92: 147-57. [CrossRef]

5. Yucel A, Senocak M, Kocasoy Orhan E, Cimen A, Ertas M. Results of the Leeds assessment of neuropathic symptoms and signs pain scale in Turkey: a validation study. J Pain 2004; 5: 427-32. [CrossRef]

6. Pagliarello C, Fabrizi G, De Felici B, Casanova D, Feliciani C, Di Nuzzo S. Notalgia paresthetica: factors associated with its perceived severity, duration, side, and localization. Int J Dermatol 2017; 56: 932-8. [CrossRef]

7. Richardson BS, Way BV, Sepeece AJ 3rd. Osteopathic manipulative treatment in the management of notalgia paresthetica. J Am Osteopath Assoc 2009; 109: 605-8.

8. Eisenberg E, Barmeir E, Bergman R. Notalgia paresthetica associated with nerve root impingement. J Am Acad Dermatol. 1997; 37: 9981000. [CrossRef]

9. Springall DR, Karanth SS, Kirkham N, Darley CR, Polak JM. Symptoms of no-talgia paresthetica may be explained by increased dermal innervation. J Invest Dermatol 1991; 97: 555-61. [CrossRef]

10. Alcantara F, Feito M, Albizuri F, Beato M, De Lucas R. Notalgia Paresthetica anf Multiple Endocrine Neoplasia Syndrome 2A: Case Report. Pediatr Dermatol 2016; 33: 303-5. [CrossRef]

11. Savk O, Savk E. Investigation of spinal pathology in notalgia paresthetica. J Am Acad Dermatol 2005; 52: 1085-7. [CrossRef]

12. Savk E, Savk O, Bolukbasi O, Culhaci N, Dikicioğlu E, Karaman G, Sendur N. Notalgia paresthetica: a study on pathogenesis. Int J Dermatol 2000; 39: 754-9. [CrossRef]

13. Savk E, Savk SO. On brachioradial pruritus and notalgia paresthetica. J Am Acad Dermatol 2004; 50: 800-1. [CrossRef]

14. Pérez-Pérez LC. General features and treatment of notalgia paresthetica. Skinmed 2011; 9: 353-8.

15. Savk E, Savk O, Sendur F. Transcutaneous electrical nerve stimulation offers partial relief in notalgia paresthetica patients with a relevant spinal pathology. J Dermatol 2007; 34: 315-9. [CrossRef]

16. Maari C, Marchessault P, Bissonete R. Treatment of notalgia paresthetica with botulinum toxin A: a double-blind random-ized controlled trial. J Am Acad Dermatol 2014; 70: 1139-41. [CrossRef]

17. Fleischer $A B$, Meade $T$ J, Fleischer AB. Notalgia paresthetica: successful treatment with exercises. Acta Derm Venereol 2011; 91: 356-7. [CrossRef]

18. Subaşı V, Çakır T, Atasoy MF. Notaljia parestetika tedavisinde kuru iğleneme ve kinezyolojik bantlama kombinasyonun etkinliği: Olgu sunumu. Turk J Phys Med Rehab 2016; 62: 273-6. [CrossRef]

Cite this article as: Kovalak E, Aydoğan Ç. Notalgia paresthetica: A rare cause of neuropathic pain. İstanbul Med J 2018; 19: 186-8. 